\title{
TIPOS DE EVENTOS DEL VIDEOJUGAR Y DIRECCIÓN DE LA ACTIVIDAD ELOCUTIVA
}

\author{
Por \\ Julián González ${ }^{1}$ \\ Universidad del Valle \\ Profesor Titular \\ Escuela de Comunicación Social \\ Cali, Colombia \\ julián.gonzalez@correounivalle.edu.co
}

\section{Olga Lucía Obando}

Dr. Phil.

Profesora Titular

Instituto de Psicología

olgaob@yahoo.de

\section{Resumen:}

Este artículo ofrece una muy sintética descripción del tipo de eventos que se despliegan durante el videojugar, en particular aquellos que anudan lo que ocurre en la pantalla (mundo del videojuego) con lo que hace el videojugador para operar el juego (mundo del juego). Al pensar la práctica de videojuego, el videojugar, como un complejo enjambre de eventos que discurren en el tiempo, y situar al videojugador en medio, este artículo sugiere que la actividad elocutiva del videojugador cumple al menos dos funciones: regula los flujos emocionales para favorecer un control adecuado de los comandos del videojuego y ayuda a ordenar el devenir de los eventos que emergen durante la interacción máquinavideojugador.

\section{Palabras-clave:}

Videojuego, cognición situada, cognición corporalizada, actividad elocutiva.

${ }^{1}$ Candidato a Doctor en Psicología 


\section{Introducción}

Examinar los eventos que emergen en una Situación de Videojuego (SVJ), discriminarlos atendiendo su distribución en el tiempo, puede ayudar a establecer relaciones inadvertidas en otro tipo de estudios sobre videojuegos. En artículos anteriores hemos expuesto el carácter de la investigación de la que deriva el presente artículo (González \& Obando, 2008 a y b; 2010 a y b), y en particular, el utillaje metodológico empleado para hacernos a una descripción minuciosa de la actividad de videojuego, diferenciando tres planos temporales de eventos en la Situación de Videojuego: el del mundo del videojuego (game event time $e^{2}$ ), es decir el mundo que discurre dentro de la pantalla de videojuego; el del (video)jugar (play event time), esto es, el de la actividad de juego del videojugador; y el plano temporal del entorno social del videojugador (social event time). También se ha presentado la codificación empleada para discriminar la actividad elocutiva del videojugador, las diversas posiciones y movimientos corporales, y los estados emocionales que pueden apreciarse a partir de un conjunto de indicios observables. Y se expusieron algunos criterios para diferenciar entre tipos de videojuegos (videojuegos de realización, de potenciación, de actualización y de virtualización), usando -en particular- distinciones introducidas por Levy (1999) ${ }^{3}$. En esta oportunidad, nos interesa presentar un aspecto particularmente diciente del modo como fenómenos aparentemente no relacionados se dan cita y convergen en la SVJ permitiéndonos apreciar de manera renovada la práctica de videojuego. Este artículo se ocupa de presentar y describir dos (2) secuencias de SVJ en que se advierten la dirección temporal e intencional de las elocuciones y las funciones regulatorias que las elocuciones ejercen respecto a la trama emocional del videojugar.

La práctica de videojuego es una valiosa oportunidad para examinar el despliegue temporal de una cognición situada, expresiva (ruidosa) y corporalizada (Perron, 2005; Griffin, 2005; Ermi \& Mäyrä, 2005; Tarja \& Rambusch, 2007; Bayliss, 2007; Fromme, 2007; Susi \& Rambusch, 2007 González \& Obando, 2008 a y b; Piscitelli, 2009; González \& Obando, 2010 a y b). El videojugador debe atender la resolución de un conjunto de problemas para los cuales no es posible contar con una comprensión completa y anticipada de los mismos. Esta condición, la imposibilidad de hacerse a una comprensión lógica previa del problema en curso, explicaría la índole particularmente ruidosa, corporalizada y situada de esta cognición, una cognición densamente atravesada por requerimientos de regulación emocional, ajuste continuo a los resultados obtenidos momento a momento, examen de alternativas con importantes restricciones de tiempo y desarrollo de tentativas a partir de meros indicios. 


\section{Tipos de eventos del videojugar en el modo juego}

Para explicar las relaciones entre actividad elocutiva y sus funciones regulatorias de la actividad cognitiva y emocional durante la actividad de videojuego es preciso referir la índole de algunos de los tipos de eventos de juego que se presentan durante el desarrollo del videojuego. Los eventos del jugar, play event, sólo se presentan en los estados en que la máquina y el videojugador están activos e interactuando, es decir, cuando el videojugador está haciendo selección o ajustes del videojuego o cuando, efectivamente, el videojugador está jugando ${ }^{4}$. Para examinar este aspecto particular, el de las relaciones entre actividad elocutiva y práctica de videojuego durante los estados 1:1, es decir, en que el sujeto opera la máquina y la máquina está en modo juego, vamos a establecer una diferenciación.

Los eventos del mundo del juego (play event), es decir, aquellos que resultan de la actividad del videojugador consideran cinco tipos, de acuerdo con los resultados: los principales son los eventos resolutorios (E-R), no resolutorios o fracasos (E-F) y de evitación (E-E). Adicionalmente, hay eventos del mundo de juego que devienen, por decirlo de un modo simple, eventos de trámite (E-T). Esto es, no entrañan un desafío importante para el videojugador, y su dominio sobre ellos ha alcanzado un grado significativo de automatización ${ }^{5}$. Cuando se alcanza pleno dominio del videojuego, en particular en aquellos videojuegos de realización, potenciación y de actualización, los videojugadores pueden derivar hacia prácticas de exploración y experimentación del videojuego, esto es, imponerse retos no previstos por el videojuego (p.e., resolverlos en el menor tiempo posible) o comenzar a investigar rutas, recursos, trucos, procedimientos alternativos para resolver el juego ya dominado. El experto se transforma entonces en virtuoso. Siempre es posible extraer, en un videojuego plenamente dominando, rendimientos virtuosos, explorando dimensiones que exceden, de lejos, la pura resolución del videojuego. En estos casos estamos ante un Evento-Experimental (E-Ex). En resumen, frente a un evento del mundo del juego (game event), el videojugador puede resolverlo, fracasar (no resolverlo), evitarlo (eludirlo), tramitarlo de manera rutinaria o experimentar (explorar).

Pero, a su vez, los eventos del mundo del videojuego (en la pantalla) pueden resultar, para el videojugador, eventos previstos, imprevistos y buscados. Los eventos previstos $(\mathrm{P})$ corresponderían, de manera exacta, a aquellos respecto a los cuales el videojugador se ha hecho a una comprensión lógica y mental, anticipada. La posibilidad de anticipar deriva de experiencias previas de videojuego en que el videojugador ha experimentado con ese (tipo de) evento o ha podido inferirlo. Los eventos imprevistos constituyen accidentes (A) y toman por sorpresa al videojugador. Los eventos buscados (B) son aquellos en que el videojugador puede realizar todas las operaciones necesarias para que el evento emerja, aparezca y se desarrolle en el curso del videojuego. Finalmente, hay momentos específicos en que en el mundo del videojuego se aglomeran, en pocas unidades de tiempo, muchos eventos: a esos estados de aglomeración de eventos les denominaremos macroeventos. 
A continuación enlistaremos los tipos de eventos de la SVJ para los estados 1:1 (ver Tabla No. 1).

Se relacionan los eventos del mundo del videojuego (A, B, P, M) con los del mundo del juego

(E-R, E-F, E-E, E-T y E-Ex):

Eventos mundo del videojuego-mundo del juego

\begin{tabular}{|c|c|c|c|}
\hline & $\begin{array}{l}\text { The Kvente de } \\
\text { mundo det } \\
\text { videofurge } \\
\text { (A, B, P, Mn) }\end{array}$ & 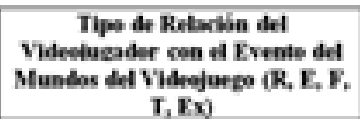 & $\begin{array}{l}\text { Tipe de evente mande del villeoforge } \\
\text { mundo del juego }\end{array}$ \\
\hline $\mathbf{1}$ & \multirow{5}{*}{ 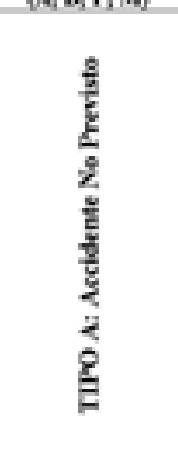 } & Tipo R-Resuetve el Aecidente & 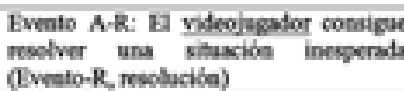 \\
\hline 2 & & Tipo E: Evita el Aosidente & 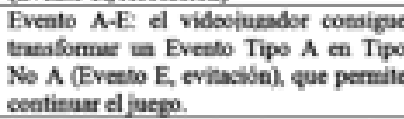 \\
\hline 3 & & $\begin{array}{l}\text { Tipo F, Fracass, so conilgate } \\
\text { resolver el acesdente }\end{array}$ & 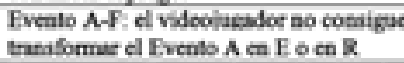 \\
\hline 4. & & $\begin{array}{l}\text { Tipo Ex: Consigoe coavertir ef } \\
\text { Evento } \boldsymbol{A} \text { ea una oportunidad de } \\
\text { experimentacion y exploraciba. }\end{array}$ & 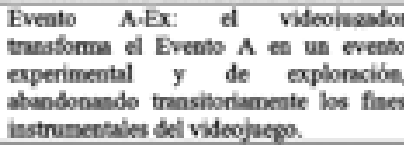 \\
\hline s. & & $\begin{array}{l}\text { No poode coevertirse en wn evenis } \\
\text { de trimite. }\end{array}$ & \\
\hline
\end{tabular}

\begin{tabular}{|c|c|c|c|}
\hline & $\begin{array}{l}\text { Tipe Everato det } \\
\text { mando del } \\
\text { videejueto } \\
\left(A, B, B_{1}, \mathrm{M}\right)\end{array}$ & 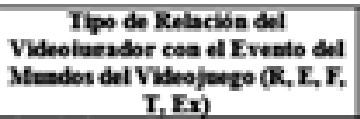 & 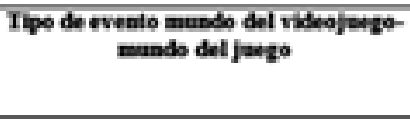 \\
\hline & & de trimite. & \\
\hline 6. & \multirow{5}{*}{ 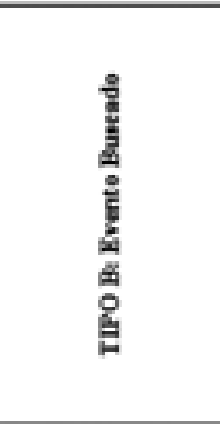 } & 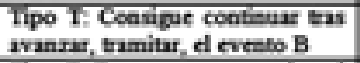 & $\begin{array}{l}\text { Evento if (evento beicado, ie } \\
\text { mantforea en evesso de trimite) }\end{array}$ \\
\hline 7. & & $\begin{array}{l}\text { Tpo F Fracasa o no resuelive el } \\
\text { Evento B }\end{array}$ & $\begin{array}{l}\text { Evento B-F el videoisandar no consiger } \\
\text { resolver el Evento B y fracasa. }\end{array}$ \\
\hline \multirow[t]{3}{*}{9.} & & $\begin{array}{l}\text { Tipo Ex Coasigue convertir el } \\
\text { Evento } 8 \text { en una oportanidad de } \\
\text { experimentacibla y exploracion. }\end{array}$ & 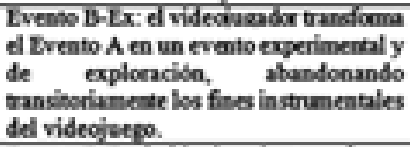 \\
\hline & & $\begin{array}{l}\text { Tipo E: Dado que es a eveato } \\
\text { bescado, stlo ea ecasiones muy } \\
\text { peculiares es evitada. }\end{array}$ & 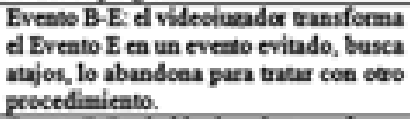 \\
\hline & & Tipo R. Ressedve al Evento. & 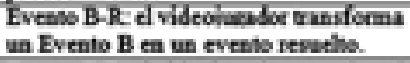 \\
\hline II & \multirow{5}{*}{ 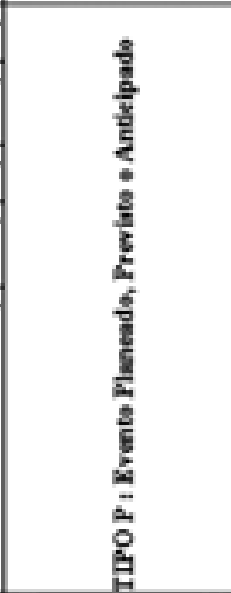 } & $\begin{array}{l}\text { Tipo R: Reverive d Evento Troo } \\
\text { P }\end{array}$ & $\begin{array}{l}\text { Evento P-R: d videoriead os remelve ed } \\
\text { evento planeado. }\end{array}$ \\
\hline 12 & & $\begin{array}{l}\text { Tipo 8. Trandorma el Evento P } \\
\text { en No P (evitindolo) }\end{array}$ & 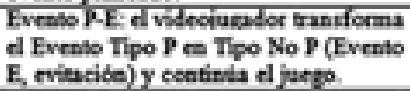 \\
\hline & & $\begin{array}{l}\text { Thpo F: Fracasa o no resutive el } \\
\text { Evento dipo P }\end{array}$ & $\begin{array}{l}\text { Evento P.F: el wideoruador fracasa al } \\
\text { eperar el eveato Tipo P. }\end{array}$ \\
\hline 14 & & Tipo T: Evento de Trimite. & 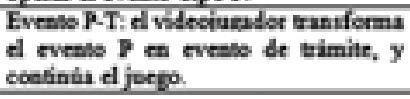 \\
\hline & & $\begin{array}{l}\text { Tipo Ex Coarigue convertir el } \\
\text { Evento } ₹ \text { en ana oportanidad de } \\
\text { experimentacibn y exploraciba. }\end{array}$ & 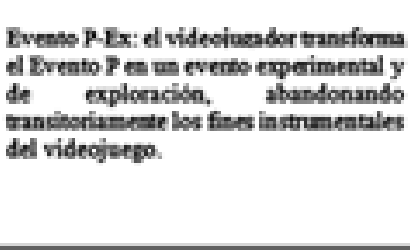 \\
\hline 16 & $\begin{array}{l}\text { Tipo } \\
\text { Mecroevento }\end{array}$ & $\begin{array}{l}\text { Coavergen en un lageo muy beeve } \\
\text { varios tpos de eventes }\end{array}$ & Varios tipos de eventos \\
\hline
\end{tabular}

Tabla No. 1 Tipos de Evento en el Estado Juego de una SVJ 


\section{Dirección de la intencionalidad y funciones de la actividad elocutiva en la práctica de videojuego: análisis de dos fragmentos de Situación de Videojuego.}

Searle (1999) ha establecido una distinción particularmente útil respecto a los actos de habla y su teoría de la intencionalidad (Searle, 1999, p. 148-152): hay los actos de habla asertivos, cuya dirección va de la palabra del hablante al mundo (word-to-world direction offit), operan como constataciones y verificaciones (verdadero/falso). Hay actos elocutivos cuya dirección va del mundo a la palabra (world-to-word), en tanto expresión de deseo, de requerimientos, de órdenes, de deberes y obediencia. Se trata de actos de habla directivos. Hay los actos de habla compromisivos, cuya dirección va del mundo a la palabra del hablante (world-to-word), implican la promesa de hacer algo. Y hay actos de habla sin ninguna dirección o expresivos, como cuando se agradece o se celebra o se rinde homenaje.

Podemos encontrar en la práctica del videojuego actos de habla o actividad elocutiva cuya dirección va de la palabra del videojugador al mundo del videojuego, esto es, se ajustan, describen, explican, reaccionan, constatan el mundo del videojuego. Son elocuciones asertivas. Se actúa y procede como si se confiara, creyera y verificara el mundo del videojuego. En estos casos, las elocuciones del videojugador parecen obedecer y responder a las demandas y regulaciones que define el mundo del videojuego. Pero hay otras elocuciones en que, por el contrario, el sujeto intenta un tipo de compromiso transformador del mundo del videojuego: aquí el sujeto ordena, opera acuerdos, intenta modificar y dirigir el mundo del videojuego o se compromete a superar la máquina, o vencer y resolver el problema de videojuego en la siguiente tentativa. Es decir, se aprecian elocuciones de compromiso y directivas vehementemente expresadas. Y finalmente, hay actos elocutivos sin dirección, puramente expresivos, en que el videojugador elogia o califica el videojuego, evalúa su propio desempeño o manifiesta su agotamiento y cansancio. Sólo si uno entiende que las elocuciones de los videojugadores son portadoras de una intencionalidad orientada a transformar y afectar el mundo del videojuego y del juego puede comenzar a comprender y situar la importancia capital de la actividad elocutiva en la SVJ.

Sugerimos que es posible usar estas distinciones para comprender la dirección y función regulatoria de la actividad elocutiva en el curso de la SVJ en relación con los diferentes tipos de eventos mundo del videojuego-mundo del juego (game-play event). Para ello presentamos un conjunto de fragmentos de una SVJ, registrada y filmada en el 2 de abril de 2010. En la SVJ participa HMG (niño, 8,4 años de edad, clase media, padres profesionales, estudiante en un colegio público de desempeño alto según clasificación ICFES, residente en Popayán). La SVJ se desarrolla entre las 3:56:42 pm y 05:33:00 pm, durante 96 minutos y 18 segundos. Para la presentación de la evidencia se hace necesario articular la argumentación con la presentación de los fotogramas de la SVJ, de modo tal que no deberían leerse como simples ilustraciones de apoyo a la argumentación, sino como elementos constitutivos de la misma. 

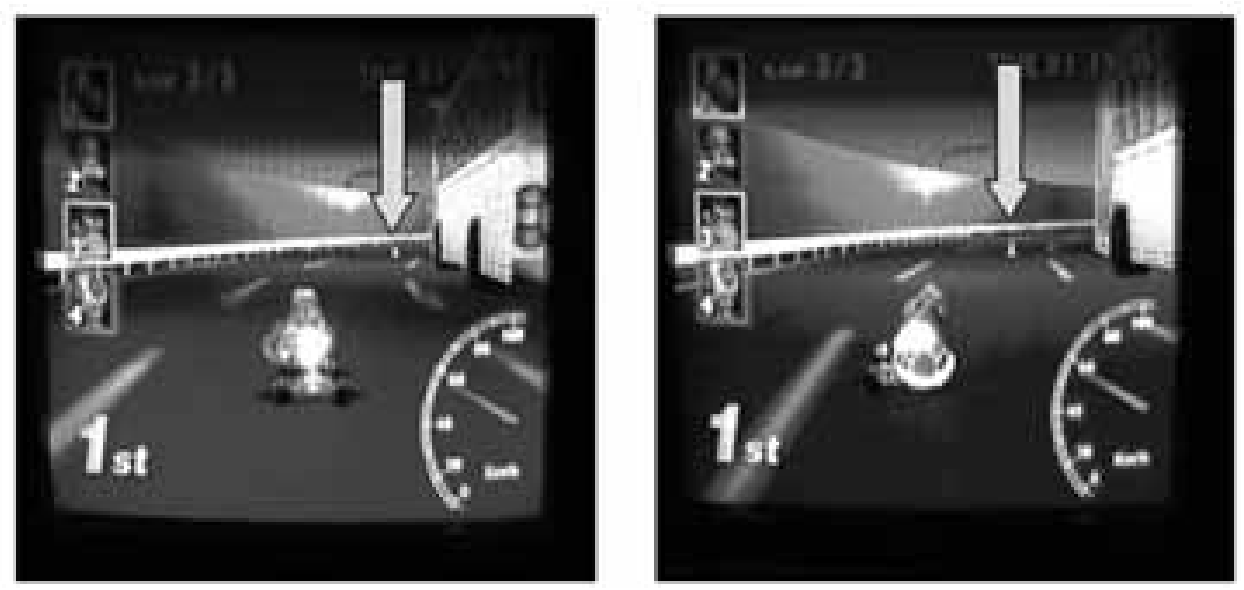

Fotograma 1 Tiempo SVJ: 00:05:59 (Horas, minutos, segundos) Fotograma 2Tiempo SVJ: 00:06:00

Estamos ante un videojuego de Realización, esto es, un videojuego en que el videojugador debe hacer continuamente elecciones (tomar a la derecha, tomar a la izquierda, acelerar, desacelerar, cambiar de dirección, topar con un objeto, evitar un objeto). Todos los videojuegos consideran este tipo de operaciones de elección, pero hay videojuegos en que predomina casi exclusivamente la práctica de hacer elecciones en tiempos muy restringidos ${ }^{6}$. Los videojuegos de peleas o los de carreras son, frecuentemente, videojuegos de este tipo. El videojuego jugado por HMG es Mario Kart 64 (Nintendo EAD, 1996) para XBOX 360. En los dos fotogramas pueden advertirse distintas estructuras de tiempo convergiendo en la SVJ: está el tiempo georreferenciado y social (fecha, hora y lugar en que se desarrolla la actividad de juego); pero -además- está también el tiempo de la SVJ7 que usa el investigador para cuantificar y situar los eventos. Pero en el mundo del videojuego también se incluyen modos de recreación del tiempo: por ejemplo, Mario Kart 64 considera un cronómetro interno que puede apreciarse en la parte superior derecha del los fotogramas. Ver, por ejemplo, el primer fotograma en que se registra 03:19:88 (minutos, segundos, centésimas de segundo).

HMG conduce su avatar (yoshi, un pequeño dinosaurio) y lidera la carrera. El primer fotograma corresponde a un pasaje de trámite (Evento T). Sin embargo, se puede apreciar al fondo un objeto, una cáscara de banano (destacado con una flecha en el fotograma). El videojugador debe controlar su avatar y evitar pasar sobre el banano (una trampa). Estamos ante un Evento A que el videojugador debe transformar en un evento No A, es decir, un evento E (evitación). En este caso, el evento A (cáscara de banano) podría derivar en evento A-E o A-F , dependiendo de las elecciones que realice el videojugador. 

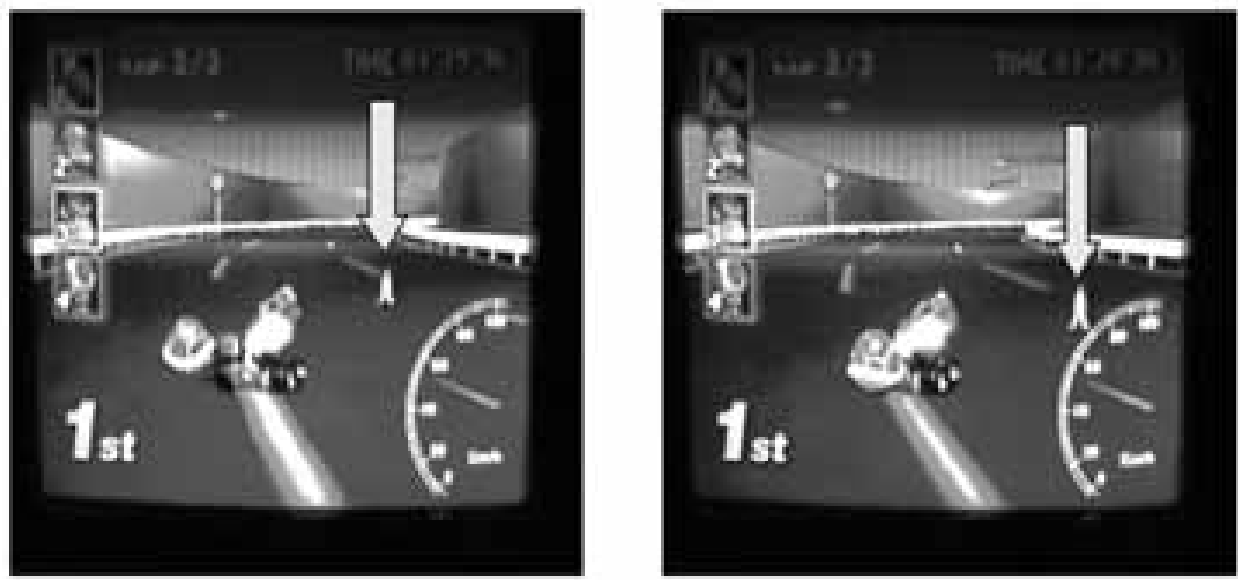

Fotograma 3. Tiempo SVJ 00:06:00 + (unas centésimas de segundo después). Fotograma 4. SVJ 00:06:00++

Unas centésimas de segundo después del fotograma 2 (ver fotograma 3) HMG realiza la siguiente elocución: “¡Ay, mamá!”’. Es una elocución que pronuncia unas fracciones de segundo antes de que su avatar tope con la cáscara de banano. Mientras exclama, HMG maniobra su avatar para evitar topar con la cáscara de banano transformando un evento A en No A (o Evento E). Esta elocución viene acompañada de una pequeña tensión del cuerpo (tira el cuerpo hacia atrás y un lado) en un movimiento que semeja el del avatar en el espacio del videojuego ${ }^{10}$. La elocución -acompañada de los reacomodos corporales y la operación de control sobre los comandos del videojuego- parece expresar y, al mismo tiempo, regular las emociones derivadas del evento A y permite una rápida adaptación a la pequeña tarea de maniobra. Pronunciada unas fracciones de segundo previas al evento A, esta elocución self-get pareciera venir del mundo del videojuego hacia el mundo del videojugador, esto, hacia las condiciones de operación de los comandos y el control del videojuego. Es decir, afecta y se articula a las intenciones y acciones del jugador. Puede reconocerse en HMG un importante nivel de excitación cuando ve aproximarse, en fracciones de segundos, el evento A (cáscara de banano), de ahí la necesidad de inhibir o controlar la excitación ${ }^{11}$ para poder operar y resolver con eficiencia el evento crítico. En este caso, el mundo del videojuego (Evento A) dirige la acción del videojugador y pareciera gatillar, entre otras, una elocución que, por decirlo de algún modo, proviene del mundo del videojuego y se dirige hacia el mundo del juego y del jugador. 


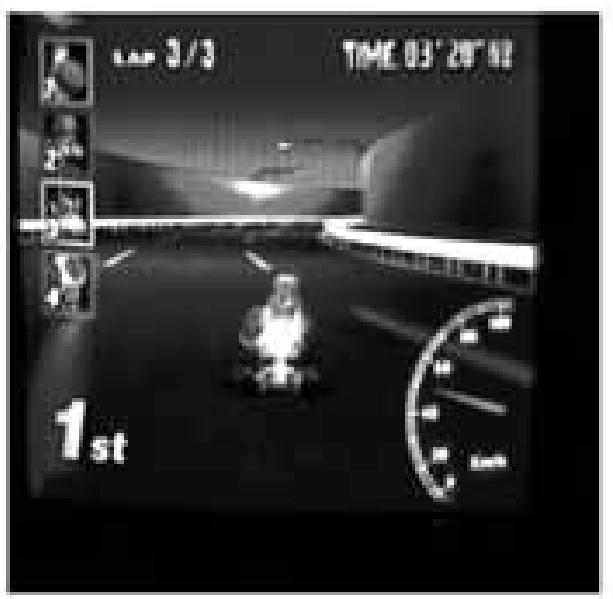

Fotograma 5 SVJ: 00:06:01.

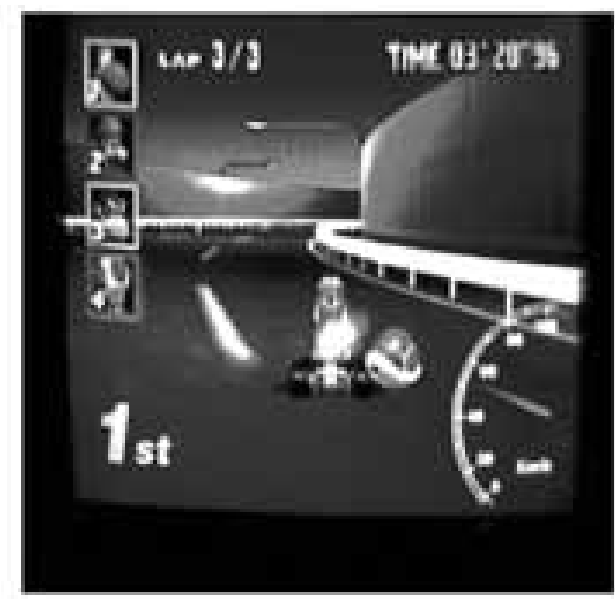

Fotograma 6 SVJ: 00:06:01+

Unas centésimas de segundos después de la elocución, el Evento A se ha transformado en No A (Evento de Evitación), y una fracción de tiempo después, en los fotogramas 5 y 6 , apreciamos cómo se desarrolla un conjunto de eventos T (de trámite). HGM ha sabido sortear el evento A.

A continuación examinaremos otro fragmento de la SVJ. El jugador controla su avatar en el fotograma 7. Es un momento crítico en que hay tres Eventos tipo A convergiendo (ver flechas en dirección de arriba hacia abajo): hay una cáscara de banano en la trayectoria, acaba de sobrepasar un camión y un avatar competidor (Donkey Kong, un mico) está a punto de sobrepasarlo. Hay también un evento tipo B: busca alcanzar y sobrepasar un vehículo que avanza hacia adelante (ver flecha en dirección de abajo hacia arriba).

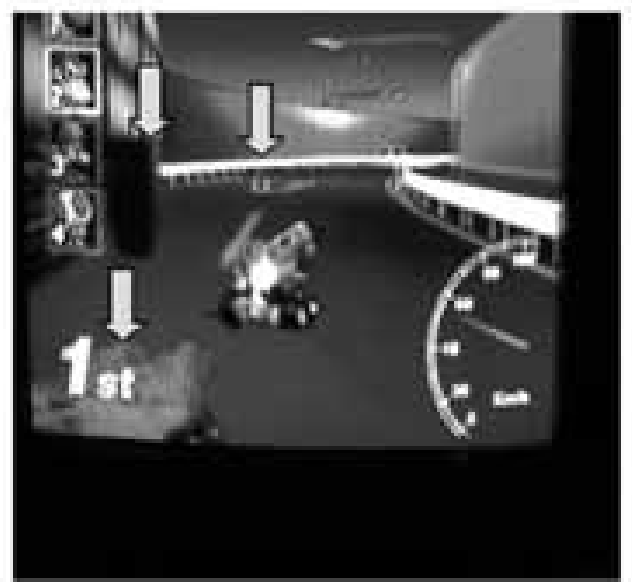

Fotograma 7 SVJ: 00:06:07

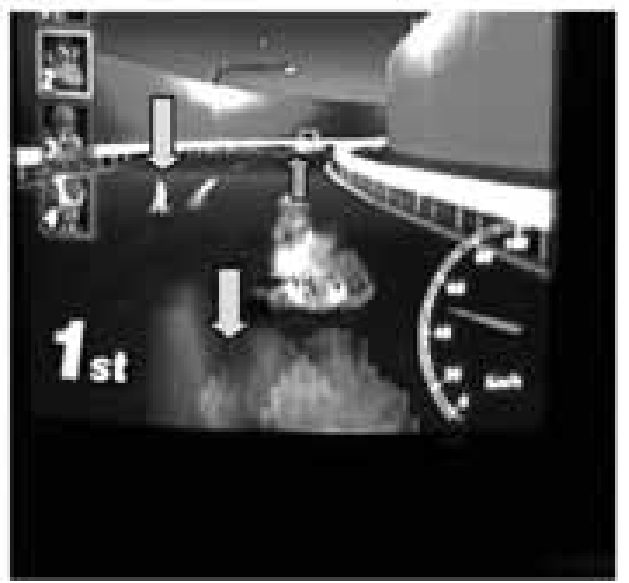

Fotograma 8 SVJ: 00:06:07+.

Posteriormente consigue avanzar y evitar al menos dos de los eventos críticos: la trampa de la cáscara de banano y la presencia del competidor. Es decir, en los fotogramas 9 y 10, los eventos A se han convertido en Eventos T, tras evitarlos (Eventos E o Eventos No A). 


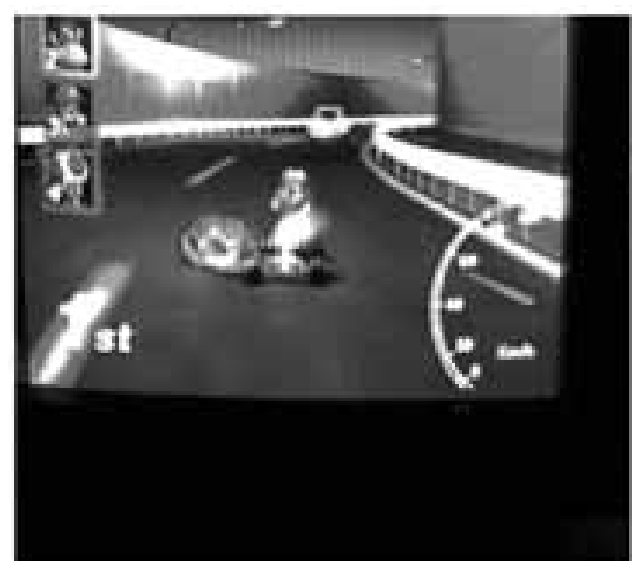

Fotograma 9 SVJ: 00:06:08.

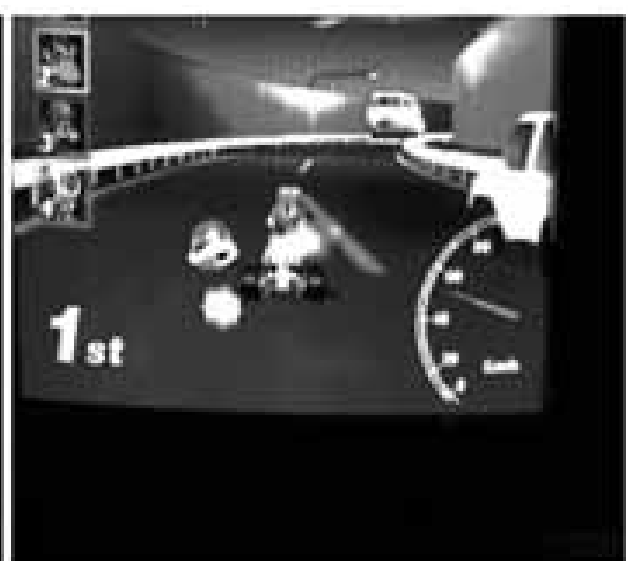

Fotograma 10 SVJ: 00:06:10.

En 00:06:10+ (ver fotograma 12) pronuncia una elocución que adquiere todo su sentido en relación con la situación específica de juego. En el fotograma 11 se aprecia cómo HMG conduce su avatar, e intenta superar a un vehículo que se mueve en el misma dirección: se trata de un evento B y de trámite (ver flecha en dirección abajo hacia arriba). Pero unas centésimas de segundo después, Donkey Kong intenta superarlo por el margen derecho. Estamos ante dos Eventos A: por un lado, se aproxima un vehículo en sentido contrario, y -por otro lado-, el competidor está a punto de superarlo. En ese momento, entre el fotograma 11 y 12, pronuncia la siguiente elocución: "Por si me pasa". Aquí quiere decir básicamente lo siguiente: "tengo este caparazón verde - un arma- por si mi competidor, el mico, me sobrepasa. Es decir, el Evento A1 (competidor a punto de sobrepasarlo) puede convertirse en Evento F (es sobrepasado) o R (Resuelve), pero no puede transformarse en un Evento E (No A, evitado). La resolución implica por dispararle al contendor el caparazón de la tortuga y retrasarlo: pero para ello debe tomar decisiones muy rápidas y coordinar los movimientos adecuados sobre los comandos para conseguir dirigir el arma contra su contendor. Pero al mismo tiempo debe hacerlo aprisa y evitar que ocurra el Evento A2 (camión a punto de colisionar), esto es, deberá transformar el Evento A2 en Evento E (No A). En otras palabras: HM deberá transformar el Evento A1 (contendor a punto de rebasarlo) en un evento P-R (previsto y resuelto), esto es, dispararle el caparazón verde, acertar y rebasarlo. 


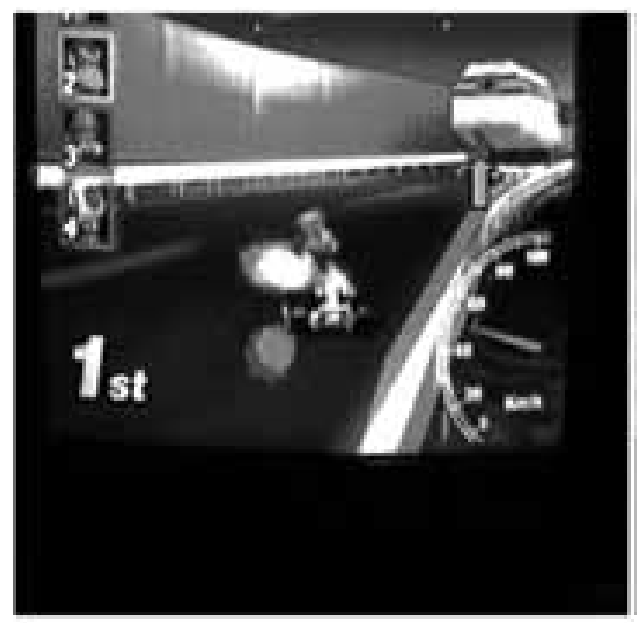

Fotograma 11 SVJ: 00:06:10

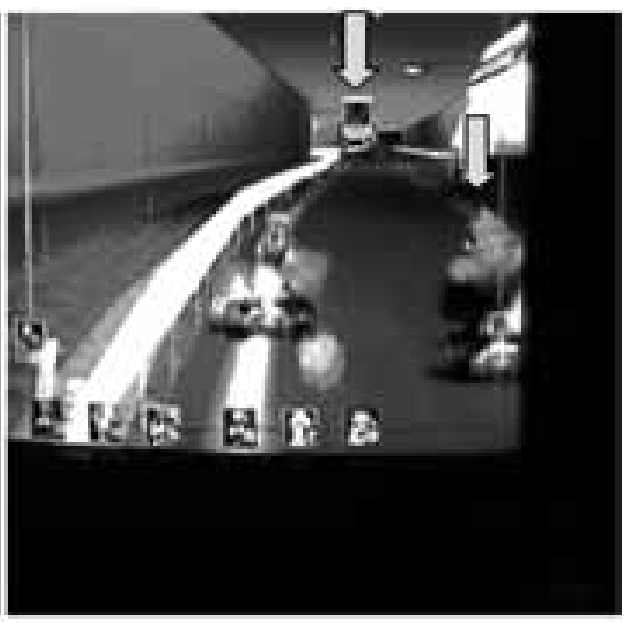

Fotograma 12 SVJ: 00:06:12

En los fotogramas 13 y 14 consigue transformar el Evento A1 en Evento P-R: unas centésimas de segundo después de la elocución, HMG maniobra su avatar, consigue abatir a su contendor con el caparazón verde, y rebasarlo (ver flecha en dirección derecha-izquierda y hacia arriba). Pero el evento A2 continúa latente.
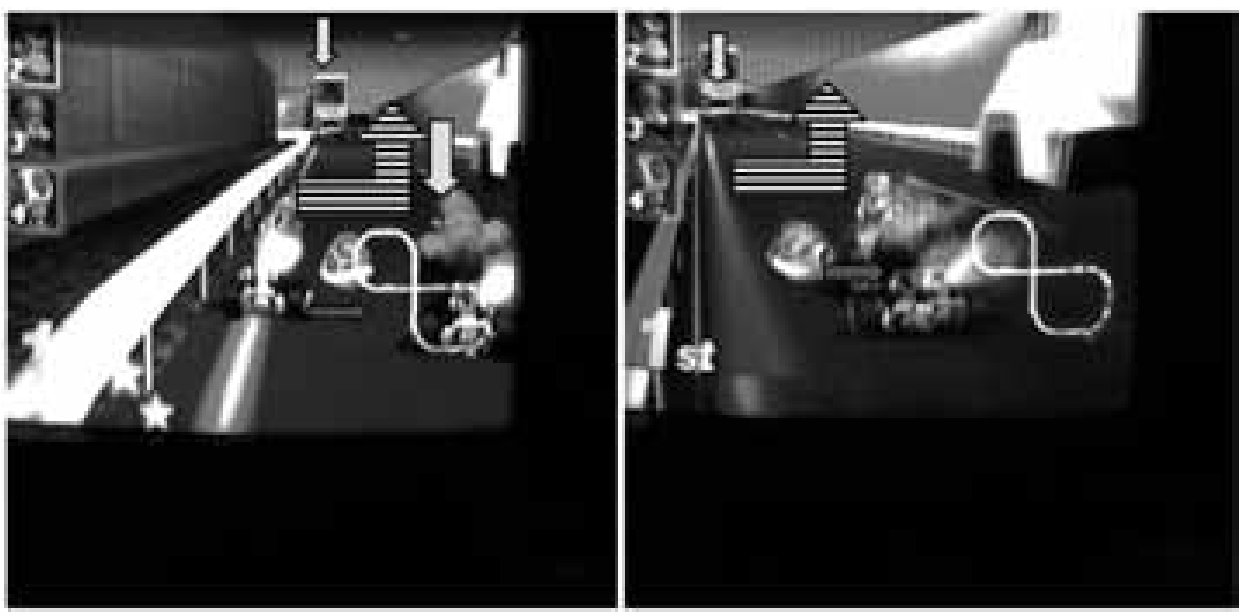

Fotograma 12 SVJ 00:06:12+. Manipula el arma Fotograma 13 SVJ: 00:06:13 Abate al contendor.

Tras conseguir finalmente superar al contendor está en mejores condiciones de transformar el Evento A2 en Evento E (No A), eludiendo el camión a los 00:06:14+ de la SVJ (ver fotogramas 14 y 15). Al final consigue efectivamente evitar la colisión. 


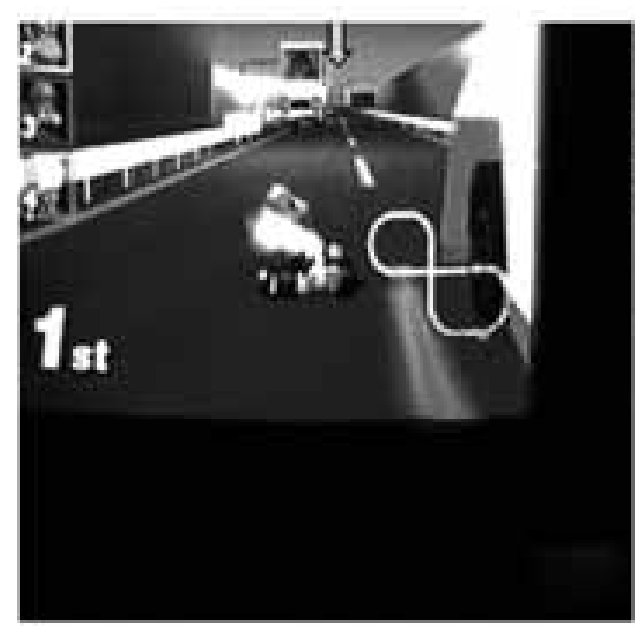

Fotograma 14 SVJ: 00:06:13.

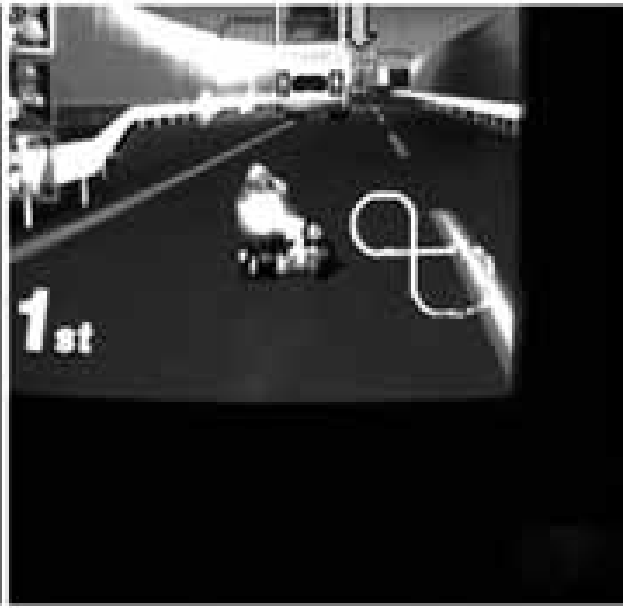

Fotograma 15 SVJ: 00:06:14.

Lo relevante en este segundo fragmento de SVJ, son tanto la dirección de la elocución como su función. Mientras la primera elocución (¡Ay, mamá!), por decirlo de un modo, se subordina a las prescripciones del mundo del videojuego (va del mundo del videojuego a la acción del videojugador), constata una condición dada, deviene asertiva; en la segunda ("Por si me pasa"), HMG ejerce dominio planificado y anticipatorio sobre el mundo del videojuego, es decir, la elocución parece moverse del mundo del videojugador (y del juego) hacia el mundo del videojuego, esto es, deviene directiva. Adicionalmente, $\mathrm{HMG}$ pronuncia la elocución como un comentario, como si pensara en voz alta, a diferencia de la primera en que exclama, casi grita. $\mathrm{Si}$ hubiera que decirlo de un modo simple: mientras en la primera elocución hay una suerte de expresión/inhibición de las emociones, en la segunda, HMG declara una idea, la elocución no constituye un recurso de control/inhibición de emociones. Aunque ambas elocuciones se pronuncian en relación con eventos que ocurrirán en el futuro inmediato (centésimas de segundos después) ${ }^{12}$, tanto la dirección de la intención como la función, respecto a la textura emocional del momento de juego, son distintas. 
El estudio de la actividad elocutiva en las SVJ nos ha permitido comprender que las elocuciones pueden diferenciarse atendiendo a los siguientes aspectos: 1) la orientación temporal de la elocución respecto a los eventos de la SVJ [elocuciones que se mueven en el corredor pasado(inmediato) $\rightarrow$ presente, en el presente inmediato, o en el corredor presente $\rightarrow$ futuro (inmediato)], 2) la orientación de la intención (mundo del videojuego $\rightarrow$ mundo del jugador o juego; mundo del jugador (o del juego $\rightarrow$ mundo del videojuego; y elocuciones expresivas, sin orientación); 3 ) las referencias a la SVJ (self-get, self-pet, self-set; referida al videojuego; no referida al videojuego); y 4) la función de la elocución respecto a la textura emocional de la práctica de juego (inhibición emocional para permitir el control operativo del juego, estimulo emocional para energizar la operación del juego, comentario de evaluación y planificación para orientar la actividad de juego). Creemos que es posible describir y comprender con un grado de detalle bastante fino el lugar que ocupan la actividad elocutiva y, por supuesto, el comportamiento corporal durante la transformación y operación de los eventos de la SVJ, y en particular, aquellos que vinculan el mundo del videojuego y el mundo del videojugador. Al examinar las relaciones entre eventos es posible concederle a la actividad de juego una significativa fuerza creativa allí donde un observador demasiado escéptico sólo encontraría acciones gatilladas por la arquitectura del videojuego y sus contenidos. Contar con instrumentos teóricos y técnicos para hacernos a buenas descripciones de lo que pasa cuando se videojuega y atender la práctica real y concreta del videojugar, y no sólo los contenidos del videojuego o las acciones y opiniones del videojugador antes, durante y después de jugar, puede ayudarnos a entender cómo, en torno a los eventos del videojuego se articula una reunión variopinta y harto compleja de fenómenos y procesos que justamente resultan particularmente eficientes, en tanto juntan, aglutinan y entrecruzan lo que en los análisis convencionales ha aparecido, durante mucho tiempo y por desgracia, separado, disectado y desarticulado.

La que presentamos es una muy pequeña muestra del tipo de relaciones que el análisis detallado y microgenético de la práctica de videojuego puede ofrecernos. La ruidosa actividad de videojuego, rica en elocuciones, parece desempeñar un papel importante en la regulación emocional necesaria para operar los comandos y para adelantar anticipaciones, afectando - en el sentido de saturando de afectos- el mundo del videojuego y la actividad del videojugador. 


\section{Notas}

1 Y tutora del proyecto de investigación doctoral "Niños que videojuegan: videojuegos que estructuran tiempos", del estudiante Julián González, del cual deriva este artículo. Esta investigación examina las prácticas de videojuego de un niño en edad escolar, haciendo un seguimiento de larga duración: durante un año se filmaron extensas sesiones de videojuego del niño, desde cuando tenía 7 años hasta cuando cumplió 8 años. Cada una de las sesiones de videojuego ha sido objeto de un detallado análisis microgenético para comprender de qué manera y a partir de qué procedimientos resuelve y experimenta los videojuegos que suele jugar normalmente. 2 Algunos de los términos empleados en la codificación de la Situación de Videojuego conservan y prolongan denominaciones en inglés para subrayar la continuidad entre nuestra propia terminología y algunas en las que se apoya, originalmente formuladas en inglés.

3 Ver al respecto Clasificar los videojuegos como tarea dinámica, González y Obando, 2008.

4 Para una comprensión de los estados de interacción máquina-sujeto ver González y Obando (2010 a). Supongamos que la máquina puede considerar dos estados (activa o 1; e inactiva, o 0); y el sujeto, dos estados, (operando la máquina o 1, y sin operar la máquina o 0). Entonces tenemos cinco estados de interacción máquina-sujeto. Los estados 1:1, en que tanto la máquina como el sujeto están interactuando activamente. Nos referimos a dos subestados: a) jugando y b) ajustando/seleccionando personajes, escenarios, modos, recursos del videojuego. El estado 1:0 (Máquina activa/Sujeto no Opera), en que la máquina está procesando (cargando archivos, encendiendo, etc; o el sujeto ha dejado la máquina en inercia). El estado 0:1, en que la Máquina está inactiva y el sujeto opera (fallo de la máquina, la máquina está apagada o el sujeto opera los controles sin efectos sobre el mundo del videojuego).Y el estado 0:0 o pausa, en que tanto la máquina como el sujeto están inactivos transitoriamente.

5 Por supuesto, todo evento del mundo del videojuego puede constituir para el videojugador, esto es, en el mundo del juego, un evento-desafío o problema. Para el videojugador bisoño el proceso sencillo de movilizar un personaje de un lugar a otro al comenzar un videojuego puede constituir un problema significativo. Para el videojugador experto, en cambio, algunos problemas del videojuego que apenas un mes antes resultaban verdaderos desafíos, se convierten - conforme aumenta su dominio y periciaen eventos de trámite. Transformar un videojuego plagado de eventos-desafío en otro plagado de eventos de trámite constituye la manifestación del pleno dominio del videojuego.

6 Los videojuegos de realización consideran dos modalidades: aquellos en que hay restricciones muy fuertes de tiempo para realizar las elecciones y aquellos en que no hay restricciones de tiempo o son bastante laxas. Operar contra el tiempo es lo que convierte una tarea abarcable y tratable en términos lógicos (anticipable) en una tarea particularmente exigente. Hacer elecciones rápidas, instantáneas, difiere de hacerlas contando con mucho tiempo para realizarlas.

7 Por ejemplo, el juego se desarrollo el sábado 2 de abril de 2010, esto es, un periodo no escolar. Toda suerte de regulaciones, privilegios y concesiones sociales le permiten al niño HMG jugar durante un poco más de una hora y media, en una máquina de videojuego propia y en su cuarto.

8 Nótese que el evento A no puede derivar hacia Evento A-R, pues no se trata de un evento que se resuelve o, dicho de otro modo, se trata de un evento cuya resolución consiste en evitarlo. Hay múltiples casos de Eventos A que pueden entrañar resoluciones.

9 Se trata de una elocución Self-Get. Para el estudio hemos diferenciado cuatro tipos de elocuciones, según si estas son motivadas o están articuladas al mundo del juego, del videojuego o el entorno social del videojugador. Hay elocuciones en que el videojugador aparece fuertemente implicado y proyectado en el mundo del videojuego (habla como si fuera un personaje más del mundo del videojuego). A estas elocuciones les denominamos self-get (refieren el sí mismo del sujeto como una proyección y parte del gameevent-time, el conjunto de eventos temporales del mundo del videojuego). Hay otras elocuciones en que el sí mismo alude al mundo del juego, esto es, aquellas en que el videojugador habla de sí mismo como jugador (self-pet, pet por play event time, o eventos del mundo del juego): por ejemplo, cuando se da ánimo - ¡voy a ganar!-, o cuando declara su victoria o derrota - ¡perdí!. Hay otras elocuciones en que el si mismo refiere al mundo social del sujeto, esto es, cuando habla de sí mismo como persona, en relación con la SVJ (v.g, "no, mamá, no quiero ir a comer, es que estoy jugando"). Se trata de elocuciones self-set, set por social event time, o eventos del mundo social. Se refiere a sí mismo como persona involucrada en una situación de juego, una práctica social similar a otras de las que tienen lugar en el devenir cotidiano del sujeto: comer, estudiar, dormir, bañarse... Y finalmente, hay elocuciones genéricas referidas al videojuego, pero en las que no hay referencia al self, como cuando el jugador hace comentarias y valoraciones sobre el videojuego; y hay elocuciones que ni refieren al self ni se relacionan con la SVJ. En este caso la elocución jay, mamá!, en la que el videojugador - proyectado en el mundo del videojuego- grita dado que ha estado a punto de caer en una trampa del videojuego, constituye una elocución self-get.

10 Este movimiento, ReAcomodo Corporal Menor (RAM) compensa, con el cuerpo físico, el movimiento que el videojugador hace en el espacio virtual del videojuego: le hemos denominado RAM compensatorio. 
11 El estudio nos ha permitido establecer varios mecanismos claves de regulación de la excitación en el curso del videojuego. El primero son los reacomodos corporales menores (RAM), que constituyen movimientos repetitivos, de alta frecuencia, situados en lugares específicos del cuerpo (movimientos cortos y repetitivos de las piernas, de la cabeza, de los brazos, etc). En segundo lugar están los RAM operativos, esto es, los movimientos ejercidos con los dedos y la manos sobre los comandos del videojuego: operar los comandos regula la excitación del videojuego, tanto así que es frecuente encontrar lo que hemos denominado operaciones sobre los comandos del videojuego sin efectos sobre el mundo del videojuego, esto es, movimientos repetitivos de pulsación de los controles aunque tales movimientos no tengan efectos sobre el desarrollo del videojuego. En tercer lugar, están las elocuciones self (self-get, self-pet, self-set), sobre todos las self-get y self-pet, fuertemente articuladas a estados de videojuego en que máquina y jugador están interactuando activamente.

${ }^{12}$ Uno de los hallazgos recientes del estudio consiste en constatar que, aunque el videojuego se juega momento a momento, en tiempo real, ese "tiempo real" aparece - en la práctica del videojuego- claramente desdoblado en tres tipos de "presente continuo": uno que es presente proyectado hacia el pasado inmediato del videojuego, esto es, hay acciones corporales y elocuciones orientadas a comentar, moderar, actuar sobre lo que aún perdura del pasado inmediato (unas centésimas, décimas o segundos atrás); hay otras que operan sobre el presente instante inmediato; y hay otras que anticipan el presente futuro inmediato (apenas unas centésimas, décimas o segundos antes). Por supuesto, también se aprecian elocuciones claramente referidas a eventos que ocurrieron unos minutos y horas antes o que anticipan lo que ocurrirá varios minutos después. Sin embargo, se trata de elocuciones y acciones mucho menos frecuentes. En otras palabras, el concepto y modelo de la presentidad (nowness examinado por Varela (1999) se puede entrever con bastante detalle al leer la trama de eventos que se dan cita durante la Situación de Videojuego.

\section{Referencias}

Bayliss, P. (2007). Notes toward a sense of embodied gameplay. En www.digra.org/dl/db/07312.19059.pdf. Obtenido el 29 de mayo de 2008.

Ermi, L. \& Mäyrä, F. (2005). Fundamental Components of the Gameplay Experience: Analysing Immersion. En www.digra.org/dl/ db/06276.41516.pdf. Obtenido el 29 de mayo de 2008.

Frome, J. (2007) Eight Ways Videogames Generate Emotion. Obtenido de http://www.digra.org/dl/db/07311.25139.pdf. Obtenido 2 de agosto de 2008

González, J. \& Obando, O. (2008a). Clasificar los videojuegos como tarea dinámica. En Revista Nexus. Escuela de Comunicación Social, Universidad del Valle. Cali.

(2008b). Mapear los eventos temporales en las situaciones de videojuegos. En Revista Nexus. Escuela de Comunicación Social, Universidad del Valle. Cali.

(2010a). Pautando los ritmos del videojugar: juego elocutivo y silencioso, juego continuo y fracturado. En Revista Nexus, Escuela de Comunicación Social, Universidad del Valle, Cali. pp. 30-49.

(2010b). Pensar con los pies: dinámicas elocutivas, corporales y emocionales en la práctica de videojuego. En Revista Nexus, Escuela de Comunicación Social, Universidad del Valle, Cali, pp.50-65.

Griffin, S. N. (2005). Push. Play: An examination of the gameplay button. En www.digra.org/dl/db/06278.09504.pdf, Obtenido el 20 de junio de 2007.

Lévy, P. (1999) ¿Qué es lo virtual? Barcelona: Paidos.

Perron, B. (2005) A Cognitive Psychological Approach to Gameplay Emotions. En www.digra.org/dl/db/06276.58345.pdf. Obtenido el 8 de agosto de 2008.

Piscitelli, A. (2009) Nativos Digitales: dieta cognitiva, inteligencia colectiva y arquitecturas de la participación. Santillana: Buenos, Aires, Argentina.

Searle, J.R. (1999) Mind, Language and Society. Philosophy In The RealWorld. Basic Books: New York.

Susi, T. \& Rambusch, J. (2007). Situated Play-Just a temporary blip? En www.digra.org/dl/db/07311.31085.pdf. Obtenido el 8 de agosto de 2008.

Videojuego Mario Kart 64 (1996). Desarrollador: Nintendo EAD. Directores: Tadashi Sugiyama \& Hideki Konno 